Filo. y Lingưr. 8(1 y 2):121-124, 1982.

\title{
NOTAS SOBRE EL VALOR SEMIOTICO DE LOS GESTOS
}

Gastón Gainza A.

La complejidad de los recursos comunicativos instituidos por los hombres en el proceso social, constituye uno de los rasgos definitorios de humanidad más relevante desde el punto de vista histórico. A la vez, da cuenta de la importancia que posee la necesidad de comunicación en el quehacer típicamente humano.

La instrumentalización de diversos sistemas de signos condiciona en tan al to grado la existencia de los hombres, que la vida social puede definirse como un proceso de programación semiótica. Así la concibe, entre otros, Ferruccio ROSSI-LANDI, en su intento de comprensión de la función social del arte. Por su parte, Umberto ECO describe, en breves páginas introductorias de su libro Signo, las múltiples facetas del comportamiento semiótico de un personaje imaginario, el señor Sigma, cuyas más elementales necesidades vitales en una circunstancia concreta de su existencia, son resueltas en virtud de la utilización de códigos comunicativos muy específicos.

La vigilia del individuo humano consiste, fundamentalmente, en el empleo constante de innumerables sistemas sígnicos, con los cuales regula tanto su propio comportamiento como el de sus congéneres. Algunos de esos sistemas poseen vigencia cotidiana; otros, en cambio, se encuentran circunscritos a actividades esporádicas o eventuales. Entre estos últimos, por ejemplo, cabe señalar el código que regula la conducta en los velatorios, sobre cuya base construye Julio CORTAZAR uno de sus relatos acerca de la familia de la calle Humboldt. Por su parte, entre los sistemas de empleo permanente, destaca el lenguaje verbal, tanto por la complejidad estructural que lo caracteriza, como por su eficacia comunicativa, interrelacionadacon el desarollo del pensamiento. A este respecto, es útil recordar la identificación de los signos lingü ísticos en relación con los restantes tipos de signos utilizados por los hombres, que propone Adam SCHAFF; señala el investigador polaco que los signos lingüísticos son los únicos susceptibles de la división entre significante y significado. Más adelante, podré volver sobre este aspecto, a propósito, justamente, de los signos mímicos.
Si bien es evidente que lo lingüístico desempeña un papel preponderante en la conducta social, ha de quedar en claro que su valor comunicativo no es, con mucho, exclusivo. Es preciso considerar, por ejemplo, que en el proceso infantil de adquisición de recursos que permiten la comunicación, el aprendizaje de la lengua siempre se presenta en relación de interdependencia con otros sistemas de comunicación; entre éstos, ciertamente, el que corresponde a movimientos somáticos imitados de los adultos que constituyen su medio familiar: visajes, ademanes, cabeceos, acompañan desde sus primeras manifestaciones los balbuceos de palabras-frases de que habla Karl BÜHLER. En la experiencia obtenida de la apreciación del desarrollo de la capacidad comunicativa, se hace patente el íntimo vínculo que existe entre el movimiento corporal y la actividad lingü ística, como lo señala S. L. RUBINSTEIN en sus Principios de Psicología General.

Por otra parte, enfrentados al problema de los orígenes de lo lingü ístico, diversos investigadores reconocen que la palabra surgió, si no después, al menos coincidentemente con la institucionalización de movimientos corporales; es ejemplar, en este sentido, la discusión que dedica a este problema Tatiana SLAMA-CAZACU, apoyándose en una importante selección de fuentes bibliográficas. Asimismo, con una perspectiva ligeramente distinta $y$, a la vez, rica en sugerencias teóricas de incalculable productividad innovadora, TRÂN DUC THAO -filósofo y lingüista vietnamita-, ha logrado poner en evidencia que la función mostrativa del proceso lingüístico emerge entre los prehomínidos como gesticulación con sentido. Es necesario recordar, en relación con lo que expongo aquí, cómo se soslayó, durante siglos, la importancia de la deixis en la constitución de lo lingüístico; desde luego, hay que reconocer que la admiración provocada por el carácter simbólico de los signos lingüísticos representativos, obnubiló el afán de conocimiento dirigido hacia el lenguaje verbal, de gramáticos y lingüistas prejuiciados por una lógica estrecha. Ilustrativas son, al respecto, estas palabras de K. BÜHLER: "El lógico tiene tendencia profesional a no ver en las palabras más que signos conceptuales" (según la traducción de Julián MARIAS). Podría agregarse a ellas que, por la misma 
razón, muchos estudiosos de lo lingüístico prescindieron, en sus reflexiones, de la comunicación, instancia global donde puede aprehenderse la armoniosa interdependencia entre mostración y representación lingüísticas. Unas breves palabras finales sobre este tema sirvan, a modo de apertura hacia una más plena comprensión de los fenómenos lingüísticos, para insistir en que todo acto comunicativo se funda en el manejo coherente de claves de orientación, materializadas en signos deícticos cuya manifestación más primitiva corresponde a movimientos de la mano.

Hay que distinguir en la llamada comunicación por medio de gestos, la mímica con que naturalmente se refuerza el hablar - esto es, la realización fonoacústica de una lengua-, de otros sistemas comunicativos, cuyos signos consisten exclusivamente en movimientos corporales.

Con respecto a la mímica, no se agota su valor semiótico en la consideración de la función expresiva que le asignan estudiosos como Charles BALLY. Sin pretender negar la importante contribución de ademanes y visajes a la necesidad manifestativa del hablar, es necesario hacer un esfuerzo analítico que permita reconocer el sistema que los grupos sociales han instituido históricamente sobre la base de gestos. En otras palabras, intento destacar el hecho de que la gesticulación comunicativa gestual obedece, lo mismo que la realizada mediante el lenguaje verbal, a principios y reglas institucionalizados en una formación social específica. Es cierto, por lo demás, que existen independientemente de las lenguas históricas, razón por la cual es posible identificar oposiciones de gestos con un mismo valor semántico, entre hablantes de lenguas diferentes, como sucede en Europa, por ejemplo. También es verdad que existen otras oposiciones de gestos de valor dialectal: es el caso de un ademán que se realiza golpeando con la palma de la mano derecha, colocada hacia abajo, la parte superior de la mano izquierda, colocada hacia adelante, el brazo en ángulo rector, con la palma dispuesta verticalmente en dirección al cuerpo y el pulgar sosteniendo los otros dedos semiempuñados. Este gesto posee en Chile, país hispanohablante, un significado obsceno, desconocido por otros grupos que hablan la misma lengua histórica.

Además, tan decisivo es el rol de la mímica comunicativa, que realizadores de cine como Ingmar Bergman, quien trabaja poniendo un énfasis extraordinario en los primeros planos, indagan exhaustivamente las posibilidades semióticas de rostros y manos. En otro ámbito, asimismo, los dibujantes de tiras cómicas deben adquirir una notable sensibilidad en oposiciones de rasgos gráficos sutiles, manifiestos en el rostro y el cuerpo todo de sus personajes, ya sean caricaturas humanas o animi'es antropomorfizados, mediante los cuales reproducen, precisamente, un sistema de gesticulación comunicativa; al par de la misma $-y$ por medio de "globos"-, reproducen la comunicación lingü ística. Nótese, en relación con esto, que una gran cantidad de dichas caricaturas han surgido en un medio anglohablante, razón por la que los "textos" incorporados en los "globos" deben ser traducidos a otras lenguas cuando la tira cómica se difunde en otros países, idiomáticamente diferentes. Sin embargo, los rasgos gráficos de la comunicación por medio de gestos son asumidos, en la mayoría de su expresión, sobre la base de una comprensión de sentido semejante.

Volviendo a las reflexiones de Ch. BALLY -perspicaz develador de los valores, comunicativos de sentimientos, voliciones, emociones, estados de ánimo y actitudes valorativas de carácter subjetivo-, puede, tal vez, situarse de manera más adecuada el problema de la expresión corporal. Existen gestos con valor de signo incluidos en sistemas históricamente instituidos en grupos sociales; como todos los signos no lingü ísticos instituidos por los hombres, sólo poseen significante (recuérdese mi anterior mención de A. SCHAFF), el cual consiste en movimientos del cuerpo codificados a base de oposiciones conscientemente adquiridas en una comunidad histórica. Tales oposiciones diferencian tanto relaciones afectivas (es decir, significados emocionales), como relaciones simbólicas (significados representativos). En la mímica que acompaña normalmente la acción verbal, predominan los significados afectivos.

Distinta es la caracterización de otros recursos corporales, independientes del uso lingüístico verbal, como la pantomima o los ademanes utilizados en el tránsito urbano, por ejemplo. Estos últimos pueden, a su vez, dividirse en dos tipos: los utilizados por los conductores de vehículos, por un lado, y los que emplean los policías que regulan el tránsito, por el otro. Debo destacar el hecho de que estos movimientos corporales han sido codificados internacionalmente, de manera que un conductor que extiende en sentido recto su brazo izquierdo fuera del vehículo en que transita, denota en todos los lugares donde el código tiene vigencia, que se propone doblar hacia la izquierda. En el mismo sentido, el gesto de un individuo que, 
mediante otro sistema semiótico: la vestimenta, reconocemos como policía, y cuyo ademán consiste en extender su brazo derecho doblado hacia arriba a la altura del hombro, con la palma de su mano vuelta hacia nosotros y sus dedos ligeramente rígidos, denota que debemos detener el vehículo en que nos desplazamos.

Podría extenderme largamente en ejemplos como los que ya he expuesto, pero mi propósito pareciera haberse logrado. Sólo me interesaba hacer explícito el carácter semiótico de la comunicación por medio de gestos $\mathrm{y}$, al mismo tiempo, la distinción que procede hacer en relación con ella, según se la considere o no vinculada al hablar. El tema queda abierto a otras muchas consideraciones que tanto abunden sobre lo ya expuesto, como ofrezcan posibilidades de análisis aquí no tratadas; entre estas últimas, por ejemplo, la de someter los sistemas de gesticulación comunicativa a una comparación con otros códigos semióticos de valor análogo. Para concluir, debo señalar que internacionalmente dejé fuera de mis reflexiones el sistema sustitutivo de la comunicación lingüística verbal que es utilizado en el adiestramiento de niños sordos, y que se materializa en movimientos de las manos fundamentalmente. Por su carácter de transpositor de sistemas de escritura lingüística antes que de lenguas vocálicas, merece, según creo, un estudio aparte.

Lisandro Gastón Gaínza Alvarez Universidad de Costa Rica y Universidad Nacional.

\section{BIBLIOGRAFIA INMEDIATAMENTE SUPUESTA:}

BALLY: 1941.

BALLY, Charles: El lenguaje y la vida. Buenos Aires, 1941. Losada, Col. Filosofía y Teoría del lenguaje. Trad. de A. Alonso. Vid.: pp. 127-130.

BUHLER 3 : 1967.

BUHLER, Karl: Teoría del lenguaje. Madrid, 3a. ed., 1967. Revista de Occidente, Col. Selecta, 18. Trad. por Julián Marías. Passim; en especial, pp. 161-208. (La cita, en pág. 191).

DIAMOND: 1974.

DIAMOND, A. S.: Historia y orígenes del lenguaje. Madrid, 1974. Alianza, Col. "El Libro de Bolsillo", Secc.: Humanidades. Trad.: Fco. Romero. Vid.: pp. 180-201.

ECO: 1976.

ECO, Umberto: Signo. Barcelona, 1976. Labor, Col. Temas de Filosofía. Trad. de Fco. Serra Cantarell. Vid.: "Proemio", pp. 5-20.

MALMBERG: 1977.

MALMBERG, Bertil: Teoría de los signos. Introducción a la problemática de los signos y los símbolos. México, 1977. Siglo XXI, Col. Lingü ística. Trad. de Alejandro Licona. Passim; especialmente, pp. 38-41, y 204-215.

ROSSI-LANDI, Ferruccio: Semiótica y estética.
Buenos Aires, 1976. Nueva Visión, Col. Semiología y Epistemología. Trad. de J. A. Vasco y R.

Graciela Manzini. Vid.: pp. 119-132. (Sobre mímica teatral, aunque implícitamente en el tratamiento de otro problema, pp. 39-51).

RUBINSTEIN: 1975.

RUBINSTEIN, S. L.: Principios de psicología general. México, 1975. Grijalbo, Col. Tratados y Manuales. Trad. por Sarolta Trowsky. Passim; la referenci, en p. 456.

SCHAFF: 1966.

SCHAFF, Adam: Introducción a la semántica. México, 1966. F. C. E., Secc. de Obras de Filosofía. Trad.: F. M. Torner. Passim.

SCHAFF: 1973.

SCHAFF, Adam: Ensayos sobre filosofía del lenguaje. Barcelona, 1973. Ariel, Col. Ariel Quincenal, 78. Trad. de Feliú Formosa y Epílogo de Jacobo Muñoz. Vid.: pp. 32-57.

\section{SLAMA-CAZACU: 1970.}

SALAM-CAZACU, Tatiana: Lengauje y contexto. El problema del lenguaje en la concepción de la expresión y de la interpretación por las organizaciones del contexto. Barcelona, 1970. Grijalbo, Col. Norte. Trad. por Carla del Solar. Passim; en especial, pp. 59-67. 
TRÂN DUC THAO: 1974.

TRÂN DUC THAO: Recherches sur l'origine $d u$ langage et de la conscience. Paris, 197. Edit.
Sociales, Coll. "Ouvertures". Passim; en especial, pp. 9-57. 